\title{
Video Case: Fascioliasis: Uncommon cause of Recurrent Biliary
} Colic

\author{
Mohamed Emara, Mohamed I Radwan, Ibrahim M Ibrahim
}

Tropical Medicine Department, Faculty of Medicine, Zagazig University, Egypt

\section{Comment}

We reported a 48 - year-old female patient with recurrent biliary colic .On abdominal ultrasound examination the common bile duct was dilated to $12 \mathrm{~mm}$ and an echogenic about $16 \mathrm{~mm}$ structure was seen at its lower end and was thought to be a stone. During ERCP an adult Fasciola worm was extracted with its head and suckers were prominent. 